\title{
What was the cause of Franklin Delano Roosevelt's paralytic illness?
}

\author{
Armond S Goldman, Elisabeth J Schmalstieg, Daniel H Freeman, Jr, \\ Daniel A Goldman and Frank C Schmalstieg, Jr
}

\begin{abstract}
Summary: In 1921, when he was 39 years of age, Franklin Delano Roosevelt contracted an illness characterized by: fever; protracted symmetric, ascending paralysis; facial paralysis; bladder and bowel dysfunction; numbness; and dysaesthesia. The symptoms gradually resolved except for paralysis of the lower extremities. The diagnosis at the onset of the illness and thereafter was paralytic poliomyelitis. Yet his age and many features of the illness are more consistent with a diagnosis of Guillain-Barré syndrome, an autoimmune polyneuritis. The likelihoods (posterior probabilities) of poliomyelitis and Guillain-Barré syndrome were investigated by Bayesian analysis. Posterior probabilities were calculated by multiplying the prior probability (disease incidence in Roosevelt's age group) by the symptom probability (likelihood of a symptom occurring in a disease). Six of eight posterior probabilities strongly favoured Guillain-Barré syndrome.
\end{abstract}

\begin{abstract}
Armond S Goldman, MD, is Emeritus Professor of Pediatrics at the University of Texas Medical Branch in Galveston, Texas. He was previously the Director of Pediatric Immunology/Allergy/ Rheumatology at that institution. His research concerns the immune system in human milk, ontogeny of the immune system, evolution of immune functions of the mammary gland, and the mechanisms of certain genetic immunodeficiencies. Correspondence: Armond S Goldman, MD, Division of Immunology/Allergy/Rheumatology, Department of Pediatrics, The Children's Hospital, The University of Texas Medical Branch, 301 University Boulevard, Galveston, Texas 77555-0369, USA (E-mail: agoldman@utmb.edu).
\end{abstract}

Elisabeth J Schmalstieg, MD, is a Clinical Assistant Professor of Neurology at the University of Texas Medical Branch in Galveston, Texas. She has a great deal of experience in the diagnosis and management of neurological diseases, including neuropathies.

Daniel H Freeman, PhD, is Professor and Director of the Office of Biostatistics at the University of Texas Medical Branch, Galveston, Texas. He has an in-depth knowledge of clinical applications of biostatistics in medicine. His primary research interests include survey sampling, categorical data analysis and community health.

Daniel A Goldman, MD MPH, is the President of Expert Health Data Programming, Inc. Over the past decade, he has devised a large-scale software system (Vitalnet) for linking and analysing health data such as birth, hospital and mortality data. He has also investigated statistical methods such as age-adjusted rates and standardized mortality ratios.

Frank C Schmalstieg, MD PhD, is Professor of Pediatrics at the University of Texas Medical Branch in Galveston, Texas. He has been Director of Pediatric Immunology/Allergy/Rheumatology in that institution. His research concerns mechanisms of congenital immunodeficiencies, including neutrophil defects and combined immunodeficiencies, as well as molecular mechanisms of inflammatory lung disease.
In 1921, when Franklin Delano Roosevelt (FDR) (1882-1945) was aged 39 years, he developed flaccid paralysis of the upper and lower extremities $^{1,2}$. The disease was diagnosed as poliomyelitis $^{1,2}$. Although motor function in his upper extremities recovered, his lower extremities remained paralysed ${ }^{1,2}$. Despite the handicap, he became the thirty-second President of the United States $^{1}$ (Figure 1). His presidency spanned the Great Depression of the 1930s and most of World War II ${ }^{1}$.

Roosevelt helped to create the National Foundation for Infantile Paralysis in the United States (founded in 1938), which funded rehabilitation programmes for victims of paralytic poliomyelitis and the development of vaccines to poliomyelitis viruses ${ }^{1,3}$. Since then, FDR has been identified with poliomyelitis, its treatment and its prevention.

The diagnosis of poliomyelitis in FDR's case was never questioned ${ }^{1,2,4,5}$. Indeed, it seemed fitting, because poliomyelitis was epidemic in the northeastern United States ${ }^{3,6,7}$, where FDR lived during the late nineteenth and early twentieth centuries. At the time, poliomyelitis was one of the few recognized causes of flaccid paralysis ${ }^{8-11}$. In 1909 Karl Landsteiner (1868-1943), the discoverer of major blood group antigens, and Erwin Popper (1879-1955), in Wilhelminenspital in Vienna, transferred the infection from the spinal cord of a nineyear-old boy who had died of poliomyelitis to a hamadryas baboon (Papio hamadryas) and a rhesus monkey (Macaca mullata) ${ }^{8}$. They suspected the agent was a virus, since the histopathology of the nervous system in infected animals resembled that of rabies. Landsteiner pursued studies with 


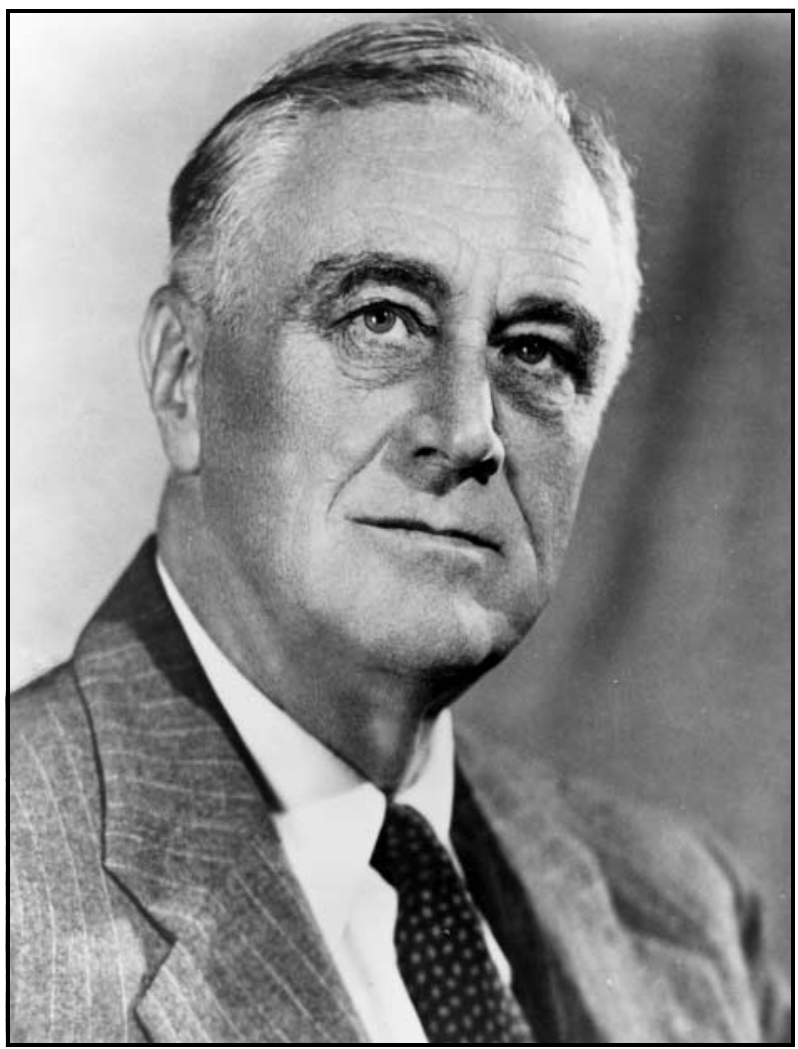

Figure 1. Photograph of President Franklin Delano Roosevelt taken in 1944 by Leon A Perskie. (By permission of Beatrice Perskie Foxman, Silver Springs, Maryland, USA.)

Constantin Levaditi (1874-1953) at the Pasteur Institute in Paris. Monkeys injected with spinal cord tissue from a 13-month-old child who had died of poliomyelitis developed neurological pathology similar to human poliomyelitis. The infecting agent was filterable and thus was a virus ${ }^{9}, 10$. Simon Flexner (1863-1946) and Paul A Lewis (1879-1929) at the Rockefeller Institute in New York City quickly confirmed the findings ${ }^{11}$.

Most symptomatic cases of poliomyelitis occurred in young children and were characterized by a mild, brief febrile illness. In a much smaller number, a second phase appeared that was marked by fever, headache, meningeal irritation, muscle soreness in the neck and back, and a flaccid, usually asymmetric paralysis. The preponderance of the disease in children was demonstrated during one of the peak epidemics (1916) in New York City, when 1469 per 100,000 children aged one to four years and only 2.3 per 100,000 adults aged 35 to 44 years developed paralytic poliomyelitis ${ }^{6}$.

Roosevelt's principal physicians during his illness were Robert W Lovett, the Chair of the Harvard Infantile Paralysis Commission, and George Draper from the Rockefeller Institute. These experts in poliomyelitis had published treatises on the subject ${ }^{12-14}$. In Lovett's 1916 publication ${ }^{14}$, the clinical types of poliomyelitis were described, including the non-paralytic form, the paralytic form, involving skeletal muscles asymmetrically, and the bulbar form, with paralysis of respiratory muscles. Furthermore, Landry's ascending paralysis and a polyneuritis were included in this classification ${ }^{14}$, although by then there was evidence that those disorders were due to a disease other than poliomyelitis. In 1859 Jean Baptiste Octave Landry (1826-1865) reported the case of a 43-year-old man with a sudden, fatal, symmetric, ascending, flaccid paralysis ${ }^{15}$. The spinal cord and brain were normal microscopically. Louis Stanislas Duménil (1823-1890) demonstrated the peripheral neuritis in the disease in $1864^{16}$. Fifteen years later, Ernst Vicktor von Leyden (18321920) pointed out the distinct microscopic pathologies of poliomyelitis (damage to motor neurons) and Landry's ascending paralysis (peripheral neuritis) ${ }^{17}$.

Then, in 1916, Georges Guillain (1876-1961) and Jean Alexander Barré (1880-1967) described the cerebrospinal fluid findings in Landry's ascending paralysis ${ }^{18}$. Two soldiers in the French Vth Army presented with ascending paralysis, loss of deep tendon reflexes, paraesthesia and pain on deep palpation of large muscles. André Strohl (18871977), a physician-scientist who became Professeur et la chaire de Physique médicale à la Faculté de Médecine de Paris in 1925, performed electromyography on the soldiers. Minor disturbances in nerve-muscle stimulation were found. Most important, their cerebrospinal fluid contained few leucocytes but a high concentration of protein ${ }^{18}$. This was the opposite of the cerebrospinal fluid findings in paralytic poliomyelitis ${ }^{3}$. This constellation of findings was named Guillain-Barré syndrome (GBS), after the first two authors.

When Lovett published his book on poliomyelitis in $1916^{14}$, other aetiologies of flaccid paralysis were not included because they were not known. In the light of the many causes of flaccid paralysis that were found later, it seemed fitting to explore whether FDR's paralysis ${ }^{1,2,19-23}$ might be due to a disease other than poliomyelitis. The most likely causes, poliomyelitis and GBS, were then investigated further by using a retrospective analytical technique devised by the Reverend Thomas Bayes (1702-1761) and published in $1763^{24}$, two years after his death.

\section{Case report}

In August 1921, when FDR was 39 years of age, he and his family went on holiday to Campobello Island, New Brunswick. On the afternoon of 9 August he fell into the cold waters of the Bay of Fundy. He was chilled but uninjured ${ }^{2,23}$.

The next day (10 August) he and his three oldest children went sailing on the Bay of Fundy. They stopped to put out a fire on the island, which took several hours, and then jogged a few miles across Campobello Island to swim in Lake Glen Severn 
and the Bay 2,23. Roosevelt later said, "I didn't get the usual reaction, the glow I'd expected"23. He walked slowly back to the house, complained of a "slight case of lumbago" 2 , felt "too tired even to dress" 23 and had chills ${ }^{2,19}$. He climbed the stairs unassisted and retired early to sleep. The chill "lasted practically all night"

The next morning (11 August), one leg was weak and by afternoon it was paralysed. That evening the other leg began to weaken. By the following day (12 August) he could not stand because of the bilateral paralysis $2,19,23$. His temperature was $102^{\circ} \mathrm{F}^{2,19}$. He "felt thoroughly achy all over" ${ }^{\prime 2,19}$. "There was no special pain along the spine and no rigidity of the neck"19. The family physician, Dr E E Bennett from Lubec, examined him and declared he had a "heavy cold"2. FDR was unable to sit unaided, presumably because of muscular weakness. His legs were numb ${ }^{20}$. Moreover:

His skin and muscles had developed a sensitivity to touch so painful that he could not stand the pressure of the bedclothes, and even the movement of the slightest breeze across his skin caused acute distress. ${ }^{2}$

By 13 August he was paralysed from the chest down. His arms, shoulders and thumbs were weak ${ }^{2,19,20}$. Dr W W Keen, a surgeon who had operated on President Grover Cleveland (1837$1908)^{25}$, was on holiday in nearby Bar Harbor, Maine $^{2}$. He examined FDR that day and diagnosed "a clot of blood from a sudden congestion - settled in the lower spinal cord"2,20. During the next few days, FDR's hands, arms and shoulders became very weak. Because he had difficulty in defaecation he required frequent enemas ${ }^{2,19}$. He could not pass urine for two weeks beginning on about 12 August $^{2,19}$ and this necessitated repeated bladder catheterizations $^{2,19}$. The fever continued for six to seven days after the illness began ${ }^{2,19}$. On 18 August he was delirious briefly ${ }^{5}$. His mental state otherwise remained normal ${ }^{2,19-23}$.

Roosevelt's wife feared that Franklin had poliomyelitis ${ }^{2,20}$. Consequently, she kept their children away from him. Roosevelt's uncle, Franklin A Delano, consulted Samuel A Levine, an internist from Boston ${ }^{21}$. According to Delano, Levine said "that it was unquestionably Infantile Paralysis"21.

On the fifteenth day of the illness, Lovett examined FDR. His temperature was $100^{\circ} \mathrm{F}$. He was paralysed from the waist down, his back muscles were very weak and there was involvement of the face and left thenar eminence. He continued to experience pain in the legs to the slightest touch and could not urinate. Lovett's diagnosis was poliomyelitis ${ }^{2,22}$.

The paralysis progressed and severe pains continued. In mid-September FDR was admitted to New York City Presbyterian Hospital. His physician, George Draper, wrote to Lovett on 24 September $1921^{22}$ :

I am much concerned at the very slow recovery both as regards the disappearance of pain ... and as to the recovery of even light power to twitch the muscles. There is marked falling away of the muscle masses on either side of the spine in the lower lumbar region, likewise the buttocks. There is marked weakness of the right triceps, and an unusual amount of gross muscular twitching in the muscles of both forearms. He coordinates on the fine motion of his hands very well now so that he can sign his name and write a little better than before.

The lower extremities present a most depressing picture. There is little action in the long extensors of the toes of each foot; a little in the perinei [sic]; a little ability to twitch the bellies of the gastrocnemii, but not really extend the feet. There is little similar power in the left vastus, and on both sides similar voluntary twitches of the hamstring masses can be accomplished.

The facial paralysis disappeared but dysaesthesia continued in the lower extremities. Other neurological findings, such as deep tendon reflexes and laboratory studies, were not mentioned. During the next six weeks, the symmetric weakness of his upper extremities and trunk subsided gradually. He was able to sit, urinate and defaecate. After discharge on 28 October 1921, the lower abdominal and lower back muscles began to strengthen. The dysaesthesia abated over a period of six months ${ }^{19}$ but the lower extremities did not improve ${ }^{2,19}$. In January 1922, his lower legs suddenly hyperflexed and "locked"1. His legs were placed in casts for three weeks and were extended gradually by "insertion of wedges behind the knees"1 1 . After the casts were removed, he was fitted with leg braces, a lower abdominal sling and crutches. He was able to stand but only with those aids.

Draper re-examined FDR on 25 March $1922^{22}$ There was little, if any, further recovery from the paralysis. The cause of FDR's paralysis was never stated in Draper's letters to Lovett ${ }^{22}$.

On 28 May 1923, Lovett re-examined FDR ${ }^{22}$ :

His arms and face and neck were normal. His bowel, bladder, and sexual functions were normal. His abdominal muscles were weak. His ability to flex from the hips was poor. From the waist down, he remained paralyzed. There was no motion in his hamstrings. His toes showed no more than a trace of motion.

In 1933, when FDR became the President of the United States, a record was made of the strength of his anterior abdominal and lower extremity muscles:

The strength in the upper abdominal muscles and the right lower anterior abdominal muscles was normal, whereas most muscles of the buttocks and lower extremities were weak except for the right first flexor digitorum brevis and the left first, second, and third flexor digitorum longus.

The muscle weakness in the lower extremities otherwise was symmetrical ${ }^{2}$.

\section{Diagnostic considerations}

In the present study, the causes of flaccid paralysis ${ }^{26-45}$ were reviewed to select the most likely diagnostic possibilities. The most probable were poliomyelitis ${ }^{26-33}$ and $\mathrm{GBS}^{26,28,31,33-45}$. Other causes of flaccid paralysis - including GBS variants, 
transverse myelitis, other viral infections and toxins ${ }^{33}$ - were not considered further because few of their features were consistent with FDR's illness.

The possibilities of poliomyelitis and GBS were then subjected to Bayesian analyses ${ }^{24,46}$. Posterior probabilities (retrospective estimates of the diagnostic probabilities of flaccid paralysis at the time of FDR's illness) were calculated by multiplying prior probabilities of a disease (relative frequencies of the two diseases in FDR's age group in the early 1920s) by symptom probabilities (likelihood of the patient's symptoms in a particular disease).

Prior probabilities were based upon the incidence of paralytic poliomyelitis in the northeastern United States during the first two decades of the twentieth century ${ }^{3,6,7}$ and of flaccid paralysis due to GBS during the last half of the twentieth century ${ }^{41,44}$. As stated above, a particularly high incidence (2.3 cases of paralytic poliomyelitis per $100,000)$ was reported for adults aged 35-44 years in New York City during the epidemic of $1916^{6}$. In 1921 (the year of FDR's paralysis) the overall incidence of paralytic poliomyelitis in the northeastern United States was estimated to be 3 per $100,000^{7}$. The true incidence of paralytic poliomyelitis was likely to have been lower, since few, if any, other causes of flaccid paralysis would have been considered at that time. About $30 \%$ of patients were adults, the vast majority of whom were under 30 years of age $\mathrm{e}^{6,7}$. Therefore the incidence of paralytic poliomyelitis in adults of FDR's age must have been much lower than the overall incidence. In the last half of the twentieth century, the overall incidence of GBS was between 0.6 and 4.0 cases per 100,000 per year ${ }^{41,44}$, and most patients were adults $28,31,33-45$.

Symptom probabilities for each disease were estimated from past reports of paralytic poliomyelitis $26-33$ and GBS26,28,31,33-45. The symptoms studied from FDR's case were:

1 an ascending, nearly symmetric flaccid paralysis that progressed for some 10-13 days;

2 facial paralysis;

3 prolonged bladder and bowel dysfunction;

4 numbness and dysaesthesia;

5 an absence of meningismus;

6 fever;

7 descending pattern of recovery from the paralysis;

8 permanent paralysis.

Deep tendon reflexes, which are diminished in both diseases ${ }^{26-45}$, were not considered because they were not mentioned in FDR's case histories. We attempted to group symptom probabilities so that each feature was an independent variable. However, some features, such as the motor and sensory deficits, have a common pathogenesis in GBS. Those features nevertheless were separated to compare their occurrences in the two diseases. Bias was not intended towards either disease in creating symptom categories.

In the Bayesian analyses, a median incidence of 1.3 cases of GBS per 100,000 per year was selected from a composite of 35 reports ${ }^{44}$. A prior probability of paralytic poliomyelitis in adults aged 3445 years $\left(2.3\right.$ per $\left.100,000^{5}\right)$ was selected from the 1916 data $^{6}$, although a more realistic value for FDR's age group in 1921 would have been significantly less ${ }^{7}$. This prior probability for paralytic poliomyelitis was modified further to account for cases of flaccid paralysis that were due to GBS (1.3 per $\left.100,000^{44}\right)$. Furthermore, it was estimated that poliomyelitis and GBS accounted for about $90 \%$ of cases of non-traumatic flaccid paralysis in FDR's age group. Thus, prior probabilities for the two diseases in adults aged 34 to 45 years in 1921 were calculated as follows: poliomyelitis, ( $(2.3-$ 1.3) $/ 2.3) \times 0.9=0.39$; GBS, $(1.3 / 2.3) \times 0.9=0.51$. The eight symptom probabilities for poliomyelitis and GBS were estimated from previous reports ${ }^{26-45}$.

\section{Results of the diagnostic analyses}

To summarize, FDR's paralytic illness was marked by: an ascending, symmetric paralysis that progressed for about 10 to 13 days 2,19,22; facial $^{2}$ paralysis in the absence of other cranial nerve abnormalities 1,22 ; prolonged bladder and bowel dysfunction 2,19,22; numbness and protracted dysaesthesia2,19,21,22; fever at the onset of the paralysis 2,19 ; a slow and symmetric partial resolution of the paralysis in a descending fashion ${ }^{2,22}$; and permanent, nearly symmetrical paralysis of the lower extremities ${ }^{2,22}$ (Table 1). Few adults who contracted paralytic poliomyelitis in the first part of the twentieth century were older than 30 years $3,6,7$. Fever, permanent paralysis and transitory bladder dysfunction are common but fever usually begins before the paralysis in poliomyelitis and the bladder dysfunction rarely lasts for more than a few days ${ }^{26-33}$. Furthermore, ascending, symmetric paralysis, facial paralysis in the absence of other cranial nerve abnormalities, obstipation, numbness and dysaesthesia are unusual or absent in paralytic poliomyelitis ${ }^{26-33}$. In that regard we found only one report of ascending, symmetric paralysis in poliomyelitis ${ }^{47}$.

In contrast, all of FDR's neurological abnormalities commonly occur in GBS $26,33-45$. His paralysis was briefly unilateral but that is not unusual in the early stages of $\mathrm{GBS}^{44}$. Minor degrees of asymmetrical paralysis, as found in FDR's case, are also common in GBS$^{41}$. Fever is uncommon in GBS but has occasionally appeared at the start of the neuritis ${ }^{45}$.

Few features of FDR's illness were consistent with other causes of flaccid paralysis $28,30-33,45$. The pure motor axonal form of acute polyneuropathy $y^{41,45,48}$ was excluded because of sensory abnormalities in FDR's disease ${ }^{19,20,22}$. Chronic inflammatory 
Table 1. Clinical features of Franklin D Roosevelt's case compared with those of Guillain-Barré syndrome (GBS) and poliomyelitis ${ }^{a}$

\begin{tabular}{llll}
\hline Clinical features & Roosevelt's case & GBS & Poliomyelitis \\
\hline Age of onset & 39 years & Mainly adults & Mainly young children \\
Flaccid paralysis & Symmetric, ascending & Symmetric, ascending & Asymmetric \\
Progress of paralysis & $10-13$ days & $10-14$ days & $3-5$ days \\
Facial paralysis & Present & Common, bilateral & Rare, save in bulbar type \\
Bladder/bowel dysfunction & 14 days & $7-14$ days & $1-3$ days \\
Numbness & Present & Common & Absent \\
Dysaesthesia & Protracted & Protracted & Absent \\
Meningismus & Absent & Absent & Common \\
Fever & Present & Rare & Common \\
Recovery from paralysis & Symmetric, descending & Symmetric, descending & Asymmetric \\
Permanent paralysis & Symmetric & In about 15\% of cases & In about 50\% of cases \\
\hline
\end{tabular}

${ }^{\mathrm{a}}$ The clinical features of poliomyelitis and GBS have been drawn from many past publications ${ }^{26-45}$.

demyelinating polyneuropathy was unlikely because the progression of the disease was not long enough in FDR's case ${ }^{45}$. The Miller-Fisher variant of GBS was unlikely because of the lack of other distinguishing features, such as ataxia and ophthalmoplegia ${ }^{41,45}$. Botulism was ruled out because there was no evidence that others in the family were exposed to food contaminated with the causative agent. Furthermore, the paralysis due to Clostridium botulinum is typically descending, and sensory abnormalities are uncommon $^{33}$. Diphtheritic polyneuritis seemed improbable because of the absence of a membranous pharyngitis within two or three months before the paralysis, the lack of palatal palsy, and the lack of the toxic appearance associated with that disease ${ }^{33}$. Bayesian analysis was restricted therefore to poliomyelitis and GBS.

It was known in 1921 that the number of leucocytes was increased and the concentration of protein usually normal in the cerebrospinal fluid of patients with poliomyelitis ${ }^{12-14}$, whereas the converse occurs in GBS ${ }^{18}$. Since FDR's cerebrospinal fluid was not examined, Bayesian analysis was limited to symptom probabilities. In the analysis, six of the eight posterior probabilities favoured the diagnosis of GBS (Table 2).

The sturdiness of the analysis was tested by determining what adjusted symptom probabilities would be required to equalize the posterior probabilities in the two diseases. With one possible exception (permanent paralysis in GBS), the adjusted symptom probabilities were much greater than the realistic symptom probabilities for each disease (Table 3). For example, for facial paralysis, which favoured GBS in the Bayesian analysis, the realistic symptom probability for poliomyelitis was 0.02 . The adjusted symptom probability required to equalize the posterior probabilities was 0.65 $([0.5 \times 0.51] / 0.39)$. One of the possible exceptions (i.e. the symptoms more likely to have been produced by poliomyelitis in the Bayesian analysis), permanent paralysis, would have favoured GBS if the prior probability for its occurrence in GBS changed from 0.15 to 0.38 (Table 3).

The sturdiness of the outcome was also tested by determining the effect of arbitrarily lowering the prior probability for GBS (originally 0.51 ) and

Table 2. Diagnostic probabilities of eight key symptoms in Roosevelt's paralytic illness appearing in Guillain-Barré syndrome (GBS) and poliomyelitis, tested by Bayesian analysis

\begin{tabular}{|c|c|c|c|c|}
\hline \multirow[t]{2}{*}{ FDR's case } & \multicolumn{2}{|c|}{ GBS (prior probability 0.51 ) } & \multicolumn{2}{|c|}{ Poliomyelitis (prior probability 0.39) } \\
\hline & $\begin{array}{l}\text { Symptom } \\
\text { probability }\end{array}$ & $\begin{array}{l}\text { Posterior } \\
\text { probability }\end{array}$ & $\begin{array}{l}\text { Symptom } \\
\text { probability }\end{array}$ & $\begin{array}{l}\text { Posterior } \\
\text { probability }\end{array}$ \\
\hline Paralysis ascends for $10-13$ days & 0.70 & 0.36 & 0.02 & 0.01 \\
\hline Facial paralysis & 0.50 & 0.26 & 0.02 & 0.01 \\
\hline Bladder/bowel dysfunction for 14 days & 0.50 & 0.26 & 0.05 & 0.02 \\
\hline Numbness/dysaesthesia & 0.50 & 0.26 & $<0.01$ & $<0.01$ \\
\hline No meningismus & 0.99 & 0.50 & 0.10 & 0.04 \\
\hline Fever & $<0.01$ & $<0.01$ & 0.90 & 0.35 \\
\hline Descending recovery from paralysis & 0.70 & 0.36 & 0.02 & 0.01 \\
\hline Permanent paralysis & 0.15 & 0.08 & 0.50 & 0.20 \\
\hline
\end{tabular}

The derivation of the estimates of prior probabilities (relative frequencies of the diseases in FDR's age range in 1921) and symptom probabilities (the chance that a clinical feature occurred in a disease) of poliomyelitis and GBS is given in the text under "Diagnostic considerations". Posterior probabilities (the probability that FDR's symptoms were due to a disease) are the products of prior and symptom probabilities. Greater posterior probabilities are in bold type. 
Table 3. The adjusted symptom probabilities in poliomyelitis and GBS needed to equalize posterior probabilities for GBS and poliomyelitis

\begin{tabular}{|c|c|c|c|c|}
\hline \multirow[t]{2}{*}{ Clinical features } & \multicolumn{2}{|c|}{ Symptom probability in GBS } & \multicolumn{2}{|c|}{ Symptom probability in poliomyelitis } \\
\hline & Original & Adjusted & Original & Adjusted \\
\hline Paralysis ascends for $10-13$ days & - & - & 0.02 & 0.92 \\
\hline Facial paralysis & - & - & 0.02 & 0.65 \\
\hline Bladder/bowel dysfunction & - & - & 0.05 & 0.65 \\
\hline Numbness/dysaesthesia & - & - & $<0.01$ & 0.65 \\
\hline No meningismus & - & - & 0.10 & 1.00 \\
\hline Fever & $<0.01$ & 0.68 & - & - \\
\hline Descending recovery from paralysis & - & - & 0.02 & 0.92 \\
\hline Permanent paralysis & 0.15 & 0.38 & - & - \\
\hline
\end{tabular}

The original symptom probabilities are taken from Table 2. A dash (-) indicates that recalculation was not indicated.

correspondingly increasing the prior probability for poliomyelitis (originally 0.39 ). Changing prior probabilities to values that were still somewhat realistic had no effect. At a prior probability of 0.09 for GBS (0.81 for poliomyelitis), six posterior probabilities still favoured GBS. But, at a prior probability of 0.08 for GBS (0.82 for poliomyelitis), four posterior probabilities still favoured GBS ("no meningismus" and "bladder/bowel dysfunction" now favoured poliomyelitis). At a prior probability of 0.03 for GBS ( 0.87 for poliomyelitis), five posterior probabilities favoured poliomyelitis ("facial paralysis" now favoured poliomyelitis).

Finally, even if the combination of GBS and paralytic poliomyelitis accounted for less than $90 \%$ of cases of flaccid paralysis in FDR's age group in 1921, the ratio of the frequency of GBS to paralytic poliomyelitis would still be 1.3. Therefore the relationships between posterior probabilities found in GBS versus those found in paralytic poliomyelitis would be unchanged.

\section{Discussion}

The case for poliomyelitis is as follows. First, poliomyelitis was the commonest cause of permanent, flaccid paralysis in infants, children and young adults in the United States during the first part of the twentieth century ${ }^{3,6,7}$. Second, the disease struck FDR during the peak of the

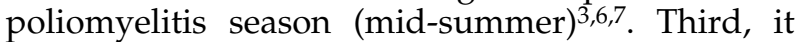
was reported that motor neurons that innervate muscles that are vigorously exercised at the start of the infection are those more likely to be involved ${ }^{49-51}$. Finally, fever usually occurs in poliomyelitis ${ }^{26-33}$.

The inconsistencies in the diagnosis of poliomyelitis are as follows. Paralysis due to poliomyelitis is rarely symmetric or ascending $26-33,47$ and usually progresses for only three to five days $26-33$. Facial paralysis is uncommon in poliomyelitis when other cranial nerves are not involved ${ }^{26-33}$. Fever in paralytic poliomyelitis usually precedes the paralysis ${ }^{26-33}$. Meningismus is common in paralytic poliomyelitis ${ }^{26-33}$ and was lacking in FDR's case ${ }^{19}$.
Numbness is very rare in poliomyelitis ${ }^{26-33}$. Pain in poliomyelitis is due to myalgia rather than dysaesthesia ${ }^{26-33}$, which was found in FDR's case $^{2,19,21,22}$. A descending, symmetric recovery from paralysis, as FDR experienced ${ }^{2,22}$, is rare in poliomyelitis ${ }^{26-33}$.

Another reason to question the diagnosis is the epidemiological pattern of paralytic poliomyelitis in the United States during the early twentieth century. At that time, almost all cases of the disease were in infants and children of pre-school age $e^{3,6,7}$. During the 1920s, schoolchildren were also prone to the infection but adults were at much lower risk $^{7}$. In 1921, few adults older than 30 years contracted paralytic poliomyelitis ${ }^{3,7}$.

The disease that most closely resembled FDR's illness was GBS, an immune-mediated attack on peripheral nerves due to molecular mimicry between foreign microbial antigens and self-antigens ${ }^{44,52-57}$ that is particularly common in adults $28,31,33-45$. In that respect, certain infections, including Campylobacter jejuni, cytomegalovirus, Epstein-Barr virus and Mycoplasma pneumoniae, often occur several days before the onset of GBS $52,53,56,57$. Cross-reactivity of $\operatorname{IgG}$ antibodies to C. jejuni with $\mathrm{GM}_{1}$ gangliosides on nerve fibres may be the commonest cause of GBS ${ }^{53-56}$.

Each neurological feature of FDR's illness was consistent with GBS26,28,31,33-45. Landry's ascending paralysis is frequent in GBS26,33-46. A symmetric pattern of paralysis is usual but seldom absolute ${ }^{41}$. Moreover, meningismus, though common in paralytic poliomyelitis ${ }^{26-33}$, was not found in FDR's case ${ }^{19}$ and is rare in GBS $26,28,31,33-45$. The aching discomfort ("lumbago") that FDR felt on the first day of his illness is common in $\mathrm{GBS}^{33,41}$ and poliomyelitis ${ }^{33}$. Numbness occurs commonly in GBS $26,28,31,33-45$ and not in poliomyelitis ${ }^{26-33}$. Furthermore, dysaesthesia occurs in about $47 \%$ of patients with GBS ${ }^{58}$ but is rare in poliomyelitis ${ }^{26-33}$.

It may be argued that FDR's paralysis was due to poliomyelitis because permanent paralysis and fever are common in poliomyelitis and not in GBS. However, fever at the onset of neuritic symptoms is found in some cases of $\mathrm{GBS}^{41}$. In 
addition, about $15 \%$ of severe cases of GBS show permanent neurological sequela ${ }^{38,39}$. In one report, around $35 \%$ of untreated patients with GBS had permanent sequelae ${ }^{59}$. Patients with GBS who are quadriplegic within the first two to five days of the illness have the worst outcome ${ }^{60}$. Furthermore, symmetric, permanent paralysis is consistent more with GBS than with poliomyelitis. As in FDR's case, the probability of full recovery of motor function in GBS is considerably less in individuals with severe, protracted paralysis ${ }^{60,61}$.

Bayesian analysis ${ }^{24,46}$ was performed to test further whether poliomyelitis or GBS was the more tenable. Prior probabilities of flaccid paralysis and FDR's other symptoms being caused by poliomyelitis or GBS in adults were estimated from previous reports. Although poliomyelitis was the principal cause of flaccid paralysis in the United States during the 1920s, few adults of FDR's age contracted the disease ${ }^{3,6,7}$. Nevertheless, to avoid a bias that favoured GBS, a higher prior probability of paralytic poliomyelitis was selected by using data from the 1916 epidemic $^{6}$. The analysis revealed that six of these eight posterior probabilities favoured GBS.

The strength of the analysis was tested further by ascertaining which symptom probabilities would be required to equalize posterior probabilities for the two diseases. The resultant adjusted symptom probabilities were unlikely. An additional test of the analysis was to determine the prior probability for GBS required for five posterior probabilities to favour poliomyelitis. The adjusted prior probability (0.03) that achieved that aim was low compared with the realistic estimate of 0.51 .

The principal laboratory tests that distinguish between poliomyelitis and GBS are cerebrospinal fluid examination, poliovirus culture, quantification of serum antibodies to polioviruses, detection of antibodies that cross-react with neural components and infectious agents such as Campylobacter, and nerve conduction studies. In the 1920s, it was known that leucocytes were increased and total protein was normal in cerebrospinal fluid from patients with poliomyelitis $3,12-14$ and that the converse was true in $\mathrm{GBS}^{18}$. However, FDR's cerebrospinal fluid was not analysed and other laboratory methods that are used to diagnose poliomyelitis or GBS were not developed until the latter half of the twentieth century. In that respect, it was unlikely that GBS would have been considered in 1921 since the characteristic cerebrospinal fluid findings in that disease were first recognized only in $1916^{18}$. Furthermore, FDR's medical management would not have changed even if he had been diagnosed with GBS because the therapeutic effects of plasma exchange and of human immunoglobulin infusions upon GBS were not established until the latter part of the twentieth century ${ }^{62-64}$.

Over 80 years after his illness, the cause of FDR's paralysis cannot be established with certainty.
Poliomyelitis cannot be ruled out but retrospective analysis favours the diagnosis of GBS. If other historical facts concerning FDR's illness surface, it will be of interest to see whether they shed further light on the nature of his crippling disease.

Acknowledgements: Paul Goldman first called to our attention the question of the diagnosis of FDR's paralytic illness. We thank Lynn Burke from the Moody Memorial Library of the University of Texas Medical Branch and the staff of Roosevelt Library and Museum at Hyde Park, New York, and Boston Medical Library in the Francis A Countway Library of Medicine, for providing key references. Susan Kovacevich provided excellent secretarial assistance, and Dr Samuel Baron from the University of Texas Medical Branch and Dr Jimmy Simon from the Bowman Gray School of Medicine of Wake Forest University made helpful suggestions during the preparation of the manuscript.

\section{References}

1 Morgan T. FDR - A Biography. New York: Simon and Schuster, 1985

2 Gallagher HG. FDR's Splendid Deception. New York: Dodd, Mead, 1985.

3 Paul JR. A History of Poliomyelitis. New Haven: Yale University Press, 1971.

4 Pascuzzi RM. American history 101: Presidents, vice presidents, and paralytic illness. Seminars in Neurology 1998;18:533-6.

5 Ditunno JF, Jr, Herbison GJ. Franklin D Roosevelt: diagnosis, clinical course, and rehabilitation from poliomyelitis. American Journal of Physical Medicine and Rehabilitation 2002;81:557-66

6 Lavinder CH, Freeman SW, Frost WH. Epidemiologic Studies of Poliomyelitis in New York City and the Northeastern United States During the Year 1916. Public Health Bulletin No. 91. Washington, DC: US Government Printing Office, 1918.

7 Nathanson N, Martin JR. The epidemiology of poliomyelitis: enigmas surrounding its appearance, epidemicity, and disappearance. American Journal of Epidemiology 1979;110: 672-92.

8 Landsteiner K, Popper E. Ubertragung der Poliomyelitis acuta auf Affen. Zeitschrift für Immunitatsforschung 1909;2: 377-90.

9 Landsteiner K, Levaditi C. La transmission de la paralysie infantile aux singes. Comptes Rendus des Séances de la Société de Biologie et de ses Filiales 1909;67:592-4.

10 Landsteiner K, Levaditi C. La paralysie infantile expérimentale. Comptes Rendus des Séances de la Société de Biologie et de ses Filiales 1909;67:787-9.

11 Flexner S, Lewis PA. The transmission of acute poliomyelitis to monkeys. Journal of the American Medical Association 1909;53:1639.

12 Peabody FW, Draper G, Dochez AR, Schlesinger EB. A Clinical Study of Acute Poliomyelitis. Monograph of the Rockefeller Institute for Medical Research No. 4. New York: Rockefeller Institute for Medical Research, 1912.

13 Draper G. Acute Poliomyelitis. Philadelphia: Blakiston, 1917.

14 Lovett RW. The Treatment of Infantile Paralysis. Philadelphia: Blakiston, 1916.

15 Landry O. Note sur la paralysie ascendante aigue. Gazette Hebdomadaire de Médecine et de Chirurgie 1859;6:472-4.

16 Duménil L. Paralysie periphérique du movement et du sentiment portent sur les quarter members. Atrophie des rameaux nerveux des parties paralysies. Gazette Hebdomadaire de Médecine et de Chirurgie 1864;1:203-6. 
17 von Leyden E. Über poliomyelitis und neuritis. Zeitschrift für klinische Medizin 1879/80;1:387-434.

18 Guillain G, Barré JA, Strohl A. Sur un syndrome de radiculonevrite hyperalbuminose du liquide cephalorachidien sans reaction cellulaire. Bulletins et Mémoires de la Société Médicale des Hôpitaux de Paris 1916;40:1462-70.

19 Roosevelt FD. Letter to Dr William Egleston, 11 October 1924, reproduced from the South Carolina Medical Association 1946;42(1). Located in: Personal correspondence of Franklin D Roosevelt and his family, Franklin D Roosevelt Library and Museum, Hyde Park, New York, USA.

20 Roosevelt E. Letter to James Roosevelt Roosevelt, 14 August 1921. Located in: Personal correspondence of Franklin D Roosevelt and his family, Franklin D Roosevelt Library and Museum, Hyde Park, New York, USA.

21 Delano FA. Letter to Eleanor Roosevelt, 20 August 1921. Located in: Personal correspondence of Franklin D Roosevelt and his family, Franklin D Roosevelt Library and Museum, Hyde Park, New York, USA.

22 The Robert W Lovett papers, B MS c39.3 and c39.4. Boston Medical Library, in the Francis A Countway Library of Medicine, Boston, MA, USA.

23 Looker E. This Man Roosevelt. New York: Brewer, Warren \& Putnam, 1932.

24 Bayes T. An essay towards solving a problem in the doctrine of chances. Philosophical Transactions of the Royal Society of London 1763;53:370-418.

25 Keen WW. The Surgical Operation on President Cleveland, Together with Six Additional Papers of Reminiscences. Philadelphia: JB Lippincott, 1928.

26 Manual for Managers of Immunization Programmes (EPI/ 89.1.1989). Geneva: World Health Organization.

27 Dietz V, Lezana M, Garcia Sancho C, Montesano R. Predictors of poliomyelitis case confirmation at initial clinical evaluation: implications for poliomyelitis eradication in the Americas. International Journal of Epidemiology 1992;21:800-6.

28 Alcala $\mathrm{H}$. The differential diagnosis of poliomyelitis and other acute flaccid paralyses. Boletin Medico del Hospital Infantil de Mexico 1993;50:136-44.

29 Mulder DW. Clinical observations on acute poliomyelitis. Annals of the New York Academy of Sciences 1995;753:1-10.

30 Jubelt B, Miller JR. Viral infections. In: Rowland LP, ed. Merritt's Textbook of Neurology (9th edn). Baltimore: Williams \& Wilkins, 1995: pp. 145-7.

31 Kidd D, Manji H, Brown D, Howard RS. Acute paralytic disease. Postgraduate Medical Journal 1996;72:699-701.

32 Adams RD, Victor M, Ropper AH. Principles of Neurology (6th edn). New York: McGraw-Hill, 1997: pp. 764-7.

33 Marx A, Glass JS, Sutter RW. Differential diagnosis of acute flaccid paralysis and its role in poliomyelitis surveillance. Epidemiologic Reviews 2000;22:298-316.

34 Löffel NB, Rossi LN, Mumenthaler M, Lutschg J, Ludin HP. The Landry-Guillain-Barré syndrome - complications, prognosis and natural history in 123 cases. Journal of the Neurological Sciences 1977;33:71-9.

35 Schoenberg BS. Epidemiology of Guillain-Barré syndrome. Advances in Neurology 1978;19:249-58.

36 Samantray SK, Johnson SC, Mathai KV, Pulimood BM. Landry-Guillain-Barré-Strohl syndrome: a study of 302 cases. Medical Journal of Australia 1977;2:84-91.

37 Kennedy RH, Danielson MA, Mulder DW, Kurland LT. Guillain-Barré syndrome: a 42 year epidemiologic and clinical study. Mayo Clinic Proceedings 1978;53:93-9.

38 Asbury AK, Cornblath DR. Assessment of current diagnostic criteria for Guillain-Barré syndrome. Annals of Neurology 1990;27 (suppl.):S21-4.

39 Ropper AH, Widjicks EF, Truax BT. Guillain-Barré Syndrome. Philadelphia: F A Davis, 1991.
40 Ropper AH. The Guillain-Barré syndrome. New England Journal of Medicine 1992;326:1130-6.

41 Arnason BGW, Soliven B. Acute inflammatory demyelinating polyradiculoneuropathies. In: Dyck PJ, Thomas PK, Griffin JW, Low PA, Poduslo JF, eds. Peripheral Neuropathy (3rd edn). Philadelphia: W B Saunders, 1993: pp. 1437-56.

42 Lange DJ, Latov N, Trojaborg W. Acquired neuropathies. In: Rowland LP, ed. Merritt's Textbook of Neurology (9th edn). Baltimore: Williams \& Wilkins, 1995: pp. 657-60.

43 Adams RD, Victor M, Ropper AH. Principles of Neurology (6th edn). New York: McGraw-Hill, 1997: pp. 1242-4.

44 Hughes RA, Rees JH. Clinical and epidemiologic features of Guillain-Barré syndrome. Journal of Infectious Diseases 1997;176 (suppl. 2):S92-8.

45 Barohn RJ, Saperstein DS. Guillain-Barré syndrome and chronic inflammatory demyelinating polyneuropathy. Seminars in Neurology 1998;18:49-61.

46 Dawson-Saunders B, Trapp RG. Basic and Clinical Biostatistics (2nd edn). Norwalk, CT: Appleton and Lange, 1994: pp. 68-9.

47 Yohannan MD, Ramia S, al Frayh AR. Acute paralytic poliomyelitis presenting as Guillain-Barré syndrome. Journal of Infection 1991;22:129-33.

48 Chowdhury D, Arora A. Axonal Guillain-Barré syndrome: a critical review. Acta Neurologica Scandinavica 2001;103: 267-77.

49 Russel WR. Poliomyelitis: the pre-paralytic stage, and the effect of physical activity upon the severity of the paralysis. British Medical Journal 1947;ii:1023-8.

50 Hargreaves ER. Poliomyelitis: effect of exertion during the pre-paralytic stage. British Medical Journal 1948;ii:1021-3.

51 Horstmann DM. Acute poliomyelitis: relation of physical activity at the time of the onset to the course of the disease. Journal of the American Medical Association 1950; 142:236-41.

52 Mishu B, Blaser MJ. Role of infection due to Campylobacter jejuni in the initiation of Guillain-Barré syndrome. Clinical Infectious Diseases 1993;17:104-8.

53 Nachamkin I, Allos BM, Ho T. Campylobacter species and Guillain-Barré syndrome. Clinical Microbiology Reviews 1998;11:555-7.

54 Kuwabara S, Yuki N, Koga M, Hattori T, Matsuura D, Miyake M, Noda M. IgG anti-GM1 antibody is associated with reversible conduction failure and axonal degeneration in Guillain-Barré syndrome. Annals of Neurology 1998; 44:202-8.

55 Goodyear CD, O'Hanlon GM, Plomp JJ, et al. Monoclonal antibodies raised against Guillain-Barré syndrome-associated Campylobacter jejuni lipopolysaccarides react with neuronal gangliosides and paralyze muscle-nerve preparations. Journal of Clinical Investigation 1999;104:697-708.

56 Hughes RA, Hadden RD, Gregson NA, Smith KJ. Pathogenesis of Guillain-Barré syndrome. Journal of Neuroimmunology 1999;100:74-97.

57 Jacobs BC, Rothbart PH, Van der Meché FGA, Herbrink $\mathrm{P}$ Schmitz PI, de Klerk MA, van Doorn PA. The spectrum of antecedent infections in Guillian-Barré syndrome: a casecontrol study. Neurology 1998;51:1110-15.

58 Moulin DE, Hagen N, Feasby TE, Anireh R, Hahn A. Pain in Guillain-Barré syndrome. Neurology 1997;48:328-31.

59 Melillo EM, Sethi JM, Mohsenin V. Guillain-Barré syndrome: rehabilitation outcome and recent developments. Yale Journal of Biology and Medicine 1998;71:383-9.

60 Ropper AH. Severe acute Guillain-Barré syndrome. Neurology 1986;36:429-32.

61 Raphael JC, Masson C, Morice V, Brunel D, Gajdos P, Barois A, Goulon M. The Landry-Guillain-Barré syndrome. Study 
of prognostic factors in 223 cases. Revue Neurologique 1986;142:613-24.

62 Guillain-Barré Syndrome Study Group. Plasmapheresis and acute Guillain-Barré syndrome. Neurology 1985;35: 1096-104.

63 Vedeler CA, Wik E, Nyland H. The long term prognosis of Guillain-Barré syndrome. Evaluation of prognostic factors including plasma exchange. Acta Neurologica Scandinavica 1997:95:298-302.

64 Plasma Exchange/Sandoglobulin Guillain-Barré Syndrome Trial Group. Randomized trial of plasma exchange, intravenous immunoglobulin, and combined treatments in Guillain-Barré syndrome. Lancet 1997;349:225-30.

It is common sense to take a method and try it. If it fails, admit it frankly and try another.

In: The Public Papers and Addresses of Franklin D. Roosevelt: Vol. I, 1928-32. New York: Random House, 1938: p. 639. 